\title{
Impact of high thermal background on diagenesis and pore evolution of reservoir - a case study from the deep water sandstone reservoir in northern South China Sea
}

\author{
JINGLAN LUO ${ }^{1}, \mathrm{CHI} \mathrm{LI}^{1}$, XIONG PANG ${ }^{2}$, CHUAN \\ LEI $^{2}$, JIANG PANG ${ }^{1}$ \\ ${ }^{1}$ State Key Laboratory of Continental Dynamics, Department \\ of Geology, Northwest University, Xi' an, China \\ ${ }^{2}$ Shenzhen Branch , CNOOC China Limited , Guangdong \\ Shenzhen 518000 , China
}

The deep water area of the northern South China Sea can be divided into three zones of low geothermal gradient (LGGZ), high (HGGZ) and thermal anomalous zone (TAZ), based on the mechanism of heating. The diagenetic-pore evolution of the sandstone reservoir of Oligocene Zhuhai Group in the deep water area is discussed in this paper. The research result shows that different geothermal gradient and heating mechanism can lead to the difference in diagenetic-pore evolution route, and influence the strength of compaction, and the type and distribution pattern of clay mineral and carbonate cements, which finally resulted in difference in reservoir quality. Thermal compaction mainly response for the primary pore loss in the HGGZ and TAZ, pore loss due to compaction was significantly higher (av. 30.4\%) than that in the LGGZ (av.25.2\%). The high geothermal gradient and heating rate accelerated the thermal transformation of clay minerals, having a great impact on the reservoirs quality. High geothermal gradient and heating rate as well as the involvement of deep thermal fluids affected the distribution of iron carbonate cement formed in the middle to late diagenetic stage. In the HGGZ and TAZ, the iron carbonate occurred in a relatively shallower depths from $1500-2500 \mathrm{~m}$ and $800-2000 \mathrm{~m}$, respectively, with the current strata temperature relatively lower $\left(80-130^{\circ} \mathrm{C} \pm\right.$ and $65-90^{\circ} \mathrm{C}$, respectively) than that in the LGGZ (depths: $3,000-4,000 \mathrm{~m} ; \mathrm{T}: 125-170^{\circ} \mathrm{C}$ ). It is of great significance theoretically and practically.

* Funded by the National Natural Science Foundation of

China (No. 41572128 , 41972129) 